\title{
A FRAMEWORK FOR ANALYZING MOBILE TELECOMMUNICATIONS MARKET DEVELOPMENT
}

\author{
Jan Damsgaard and Ping Gao \\ Department of Informatics, Copenhagen Business School, Denmark
}

\begin{abstract}
Current research focuses on the dynamics of mobile telecommunications market either from the perspectives of technology innovation or service adoption. However, because there is a mutual dependency between them, each perspective alone can only partly explain the pace and direction of change we currenly witness in this market. This article combines them into one framework to pursue a holistic understanding of mobile telecommunications market innvoation. To test its explanatory power, we apply this framework to dissecting the case of China based on second-hand data. It concludes that our model enables a systematic description on the mutual influence of infrastructure innovation and innovation adoption that moves beyond unilateral accounts. Our framework also captures the interplay between mobile telecommunications market and the social network formed by interrelated providers, users and institutions.
\end{abstract}

Key words: infrastructure; innovation; mobile telecommunications; market.

\section{INTRODUCTION}

Recent decades bear witness of the dramatic changes in mobile telecommunications technology and service. This phenomenon raises wide research interests as the availability and widespread adoption of advanced telecommunication technologies are linked to the economic potential of nations. 
Generally people study the dynamics of mobile telecommunications market from two distinct perspectives, either technology innovation or service adoption. As examples of innovation studies, Edquist (2003) reports the results of a collection of papers that draw upon systems of innovation theory to investigate the innovation of Internet and mobile telecommunications technology. Choudrie et al (2003) provides an example of using institutional theory, specifically the model of King et al (1994), to analyze the role of government in promoting the broadband technology diffusion. There are also a lot of research efforts to explain the adoption of mobile telecommunications by users (see e.g. Pedersen et al., 2003), for which Diffusion of Innovation theory (Rogers, 1995), Theory of Reasoned Action (Ajzen, 1980) as well as its extensions like Technology Acceptance Model (Davis 1989) serve as major analytical tools.

Mobile telecommunications market is built upon networkedtechnologies and infrastructure. Its transformation involves evolutionary innovation in one technology paradigm like $2 \mathrm{G}$, and the revolutionary transition from one paradigm to the next for example from $2 \mathrm{G}$ to $3 \mathrm{G}$ (Muller-Veerse, 2000). We argue that technology innovation or service adoption perspectives alone can only partly explain the mobile telecommunications market change. In this article we combine the two perspectives into one framework to pursue a holistic understanding of mobile telecommunications market innvoation.

This paper is organized as follows. In the second section we review innovation and adoption theories and their applications in studying telecommunications market innovation. The third section describes our framework, and the research questions it may address. In the fouth section we dissect four cases based on data from literature, which may preliminarily justify the explainatory power of our model. The last section derives conclusion, and discus the limitations and future work.

\section{INNOVATION AND ADOPTION TRAITS}

In literature there have been two major ways to understand the market development, either from infrastructure innovation or adoption of innovation perspectives. These two perspectives are condensed in Table 1.

Table 1. Summary of infrastructure innovation and innovation adoption perspectives

\begin{tabular}{lll}
\hline & Infrastructure innovation & Innovation adoption \\
\hline Key Drivers & Innovation of infrastructure and technology & User value \\
$\begin{array}{l}\text { Unit of } \\
\text { analysis }\end{array}$ & Networks of organizations, diverse & Users \\
& communities, different institutional actors &
\end{tabular}




\begin{tabular}{|c|c|c|}
\hline & Infrastructure innovation & Innovation adoption \\
\hline $\begin{array}{l}\text { Viewpoint of } \\
\text { diffusion }\end{array}$ & $\begin{array}{l}\text { Longitudinal process that stretches over a } \\
\text { considerable amount of time and space }\end{array}$ & Single point or short period \\
\hline $\begin{array}{l}\text { Key } \\
\text { theoretical } \\
\text { references }\end{array}$ & $\begin{array}{l}\text { Institutional theory (King et al, 1994); } \\
\text { Network economics (Arthur 1989, 1990; } \\
\text { Van de Ven, 1993); Systems of innovation } \\
\text { (Dosi et al, 1988; Edquist, 1997) }\end{array}$ & $\begin{array}{l}\text { Diffusion of innovation } \\
\text { theory (Rogers, 1995; } \\
\text { Tornatzky and Klein, 1982); } \\
\text { Theory of Reasoned Action } \\
\text { (Ajzen, 1980) }\end{array}$ \\
\hline $\begin{array}{l}\text { Typical } \\
\text { examples }\end{array}$ & (Choudrie et al, 2003; Edquist, 2003) & $\begin{array}{l}\text { (Anckar and D'Incau, 2002; } \\
\text { Pederson et al, 2003) }\end{array}$ \\
\hline
\end{tabular}

\subsection{Market Market development as a result of innovation adoption}

An innovation is an idea or concept that is new to the unit of adoption that autonomously can decide to adopt or refrain from doing so. In line with diffusion of innovation theory (DOI), the transformation of mobile telecommunications market is the result of technology and service adoption by the users. DOI identifies four elements that characterize a successful diffusion process of an innovation: 1) an innovation and its characteristics, 2) that they are communicated through specific channels 3 ) to the members of a social system 4) over time. General factors that have been found to influence adoption include adopter characteristics, the social network, the communication process, the characteristics of the promoters, and the innovation attributes which include triability, relative advantage, compatibility, observability and complexity (Rogers, 1995).

Theory of Reasoned Action (TRA) and its extensions like Technology Acceptance Model are another set of theories that address technology adoption (Ajzen, 1980; Davis 1989). Like DOI, these models predict diffusion of innovation over time and space by associating a set of variables with an adoption outcome (Wolfe, 1994). Often people incorporate DOI theory with these models to find the best mix of innovation characteristics that increases adoption. Accordingly, scholars have applied adoption models to explain diffusion with a small set of factors, like relative advantage, compatibility, complexity, management support, champion, size, centralization, and technical sophistication (Tornatzky and Klein, 1982).

Overall, the technology adoption tradition is founded on a desire to explain individual adoption decisions within the adopting unit. The adoption population is assumed relatively homogeneous with well-defined boundaries. The adoption decision is usually considered an atomic event, and the implementation stretches over limited time (months rather than years). Learning is seldom involved after the adoption, and not considered as a part of the adoption process (Lyytinen and Damsgaard, 2001). In current 
literature adoption models have remained popular means to explain adoption of mobile service (Anckar and D'Incau, 2002; Pederson et al., 2003).

\subsection{Market development as a process of infrastructure innovation}

In general, although the traditional adoption theories have provided many useful insights to understanding the diffusion of technological innovations in the past, recent empirical studies of the diffusion of complex, networked information technology like B2B infrastructure point out its limitations (Lyytinen and Damsgaard, 2001). The diffusion of a technology is not only a consumer matter or "user-pull". It also depends on the "technology-push" which should take into account the characteristics of technology. Two technological characteristics are in particular essential in understanding the infrastructural features of telecommunications technology: its reliance on standards, and its networked properties with strong network effects (Arthur, 1990). Meanwhile, the researchers should not only emphasize user adoption issue but also take into account the roles of broader mobile telecommunications market stakeholders including for example equipment vendors, network operators, content providers, government, and intragovernmental organizations in promoting the market innovation. Institutional theory (King et al., 1994), systems of innovation theory (Dosi et al, 1988; Edquist, 1997), and network economics (Arthur, 1989, 1990; Van de Ven, 1993) have been used to tackle these social and technological problems. Significantly different from DOI and other adoption theories, these theories emphasize infrastructure traits of mobile telecommunications market innovation.

Institutional theory. The institutional theory analyzes the necessary involvement of institutions in promoting infrastructure innovation and the market transformation. From this perspective, the innovation of mobile telecommunications infrastructure will be possible only if coordinated action takes place, for which institutions play an important role. Institution encompasses relevant legislative and regulative bodies and associated scientific communities (Van de Ven, 1993). The institutional measures of building an infrastructure include mobilizing bias around the technology, educating potential adopters, setting common standards, and influencing the operator to choose networks (King et al., 1994). The deployment of mobile infrastructure has been examined from the institutional perspective. For example, drawing upon the model of King et al. (1994), Choudrie et al. (2003) describes generic institutional measures that further innovation production and diffusion in Korean broadband market. 
Systems of innovation. The mobile telecommunications market is socially constructed. The researchers should not only focus on the users from an adoption perspective, but also study the roles of other stakeholders in promoting the diffusions. The technology innovation must be based on the establishment of an ecologic social system that is characterized by the efficient cooperation between different actors based on a specific business model (Star and Ruhleder, 1996). Hence the study of innovation and diffusion of complex technological systems, like mobile telecommunications infrastructure, must involve the theory of systems of innovation (Edquist, 1997), which allows the researchers exploring the social network around the technology instead of focusing on marketing strategies and changes in consumer behavior. There have been some efforts of drawing upon systems of innovation theory to investigate the innovation of Internet and mobile telecommunications technology (Edquist, 2003).

Network economics. The logic of adoption rationale is captured by the concept of network externalities (Oliva, 1994). In general, the usability of a networked technology increases with the number of adopters. This means that the benefit of being an early adopter can be relatively low compared to being a "laggard". Network externalities make it beneficial to postpone adoption until most partners have adopted and a network has been formed. This is especially true when there are several competing and incompatible alternatives (Shapiro and Varian, 1999).

Under the condition of positive network externalities once the number of adopters reaches a certain level the diffusion process will self-evolve rapidly until a saturation point is reached, or a better innovations disturb the balance. The stability and static nature of an established infrastructure comes at a price after the technology trajectory is locked-in to a certain path (Arthur, 1989). The lock-in effects can seriously slow down the innovation of technology. Often established monopoly infrastructures stand as insurmountable barriers to the adoption of new (and more advanced) technologies. As an example, Damsgaard (2002) applies network economics to analyze the development of Internet portal market.

\section{DYNAMICS OF INNOVATION AND ADOPTION: A FRAMEWORK}

We challenge current work that generally treats the mobile telecommunications market change from either infrastructure innovation or innovation adoption perspective. Based on specific sets of theories, both perspectives offer plausible explanations as to why a complex socialtechnological system diffuses (Table 1). Yet we argue these two 
fundamental perspectives are not exclusive but complement, and they are interdependent not separate. The innovation adoption drives the infrastructure innovation and vice versa. A self-enforcing spiral of mutual re-enforcement of both infrastructure innovation and innovation adoption can unfold under favoriate circumstances. We next will build a model that combines the individual adoption decision with infrastructure innovation (Figure 1).

First, mobile telecommunications services are based on complicated technologies where the mobile phone itself is just a small fraction of the various components that need to be in place for the proper operation and use of the technologies. Examples of components are applications, services, networks, handsets, standards. These interdependent components together comprises a sophisticated infrastructure (Muller-Veerse, 2000). The mobile telecommunications market is built upon this infrastructure. In other words, the infrastructure supports a series of technology applications and enables different sorts of services for the potential adoption of the users. From diffusion of innovation perspective it is clear that individual users will only adopt a technology insofar it is perceived superior to not to adopt it (Rogers, 1995). This is as perceived by the potential adopters based on the fit between the technology's immediate properties like usability and accountability, and adopters' characteristics for example education and financial background, gender and age etc (Ajzen, 1980). In return, the situation of user adoption on services and technology influences the innovation of infrastructure so that appropriate services can be offered. Mobile telecommunication infrastructure is emergent in nature and it is not only built but also grown (Ciborra, 2000). As an example, GSM system started with major providing voice communications. Afterwords SMS services was enabled. As this service is provided through control channel which means it does not involve additional cost for the operator hence a low price has been set for its consumption, and at the same time it is convenient to use for customers, it turned to be a welcomed service. This encouraged the operators to extend SMS to business field, and promoted the market to move from $2 \mathrm{G}$ to $2.5 \mathrm{G}$ that was capable of providing better data services. Hence, as we have argued above, the change of mobile telecommunications market covers the issues of both infrastructure innovation and innovation adoption. These entities are depicted in the top part of Figure 1.

The interrelance between infrastructure innovation and innovation adoption can get proof from network economics. Because a telecommunications service is dependent on a supporting infrastructure the analysis on user adoption must be expanded to take networked properties, standard depended features, and institutional arrangements into account. For networked technologies, each individual adoption decision affects the value 
of using the technology. It adds one vote in favor of a technology. This creates a positive feedback loop directly linked to the actual adoption and consequently it must be incorporated into the diffusion analysis (Arthur, 1990). The continuous growth of the complex technology also changes the properties of the innovation as perceived by the potential adopters. It lowers adoption risks and creates a bias towards the technology. It also guarantees stability of the promoted technology, triggers learning and thereby reduces costs. At the same time, the emergence of the infrastructure lowers the knowledge threshold to adoption and reduces the complexity of the technology (Attewell, 1992). The infrastructure also invites technology providers to produce standard compliant products and services. In combination, this shifts the innovation's properties in favor of adoption. Meanwhile, the infrastructure that favors adoption can over time become an inertia that constrains innovation (Van de Ven, 1993). Hence, whilst the market becomes firmly established it locks the technology properties into a certain trajectory (Arthur, 1989). The innovation is thus a process of path dependency and path creation. This explains why in most countries the mobile telecommunications markets have been transformed from $2 \mathrm{G}$ to $3 \mathrm{G}$ via a phase of $2.5 \mathrm{G}$ technology, and why for $3 \mathrm{G}$ system there are two major international standards existing in parallel that are respectively based on two $2 \mathrm{G}$ systems used now.

Second, the market transformation involves a social system, which is composed by interrelated providers, users and institutions as is depcited in the lower part of Figure 1. In the light of King et al. (1994), here institutions cover government and public authorities, trade and industry associations, and standard setting bodies. Furthermore, there is an interplay between market innovation and social system. On the one hand, as the industry evolves and the market matures there are varied providers involved according to technological requirement. For example, in $2 \mathrm{G}$ market the network operators alone control the market, but for $3 \mathrm{G}$ market there exists a provider community composed by manufactures, network operators, service providers, content providers, and service aggregators etc. Firms will carve out their specific roles and create firm-specific value chains. Depending on their specific resources and core competencies, players will position themselves differently, resulting in different overall value systems (Maitland et al., 2002). On the other hand, the three groups of actors work together to promote the market innovation. A specific actor may participate in and influence the market in different ways. For example in $2 \mathrm{G}$ system the regulators in general enacted a license through a "beauty match" method, but for $3 \mathrm{G}$ market several countries preferred bidding and charged a large sum for one license. As another example, in $2 \mathrm{G}$ market the network operators 
was dominant, but in $3 \mathrm{G}$ market it is supposed that the content providers are the "kings" (Muller-Veerse, 2000).

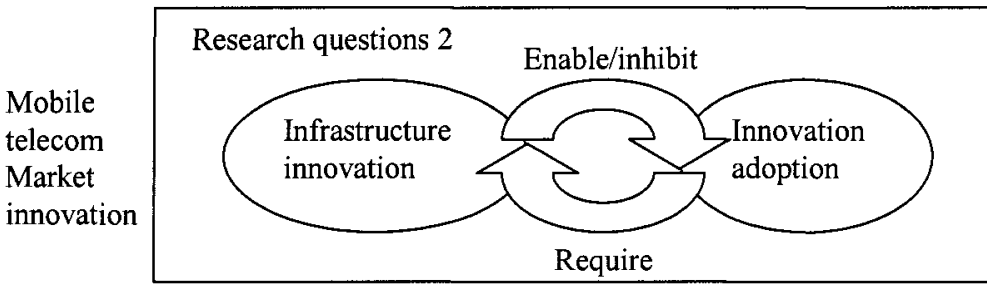

Research question 3

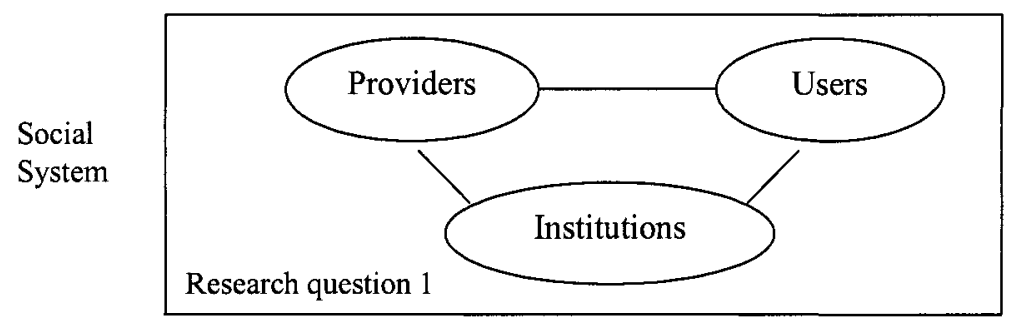

Figure 1. A framework for analyzing mobile telecommunications market innovation

Figure 1 provides a framework for us to capture and explain mobile telecommunications market innovation. According to it we should examine the interrelated action and actor layers of the market. The framework facilitates answering the following questions.

1. What actors is the social system composed of? What are the characteristics of their interactions in the social system? What are their roles in the mobile telecommunication market innovation?

2. How does the mobile telecommunications market transform? How do the infrastructure innovation and innovation adoption co-depend? What is the role of path dependence and path creation for infrastructure innovation and innovation adoption?

3. How does the social structure determine the market development, and in return how does the market development situation influence the characteristics of the social system? 


\section{A CASE STUDY}

Our framework is suitable to study mobile telecommunications market innvoation, for example the transformation from $2 \mathrm{G}$ to $3 \mathrm{G}$. Our concern is with highly complex processes that take several years to unfold. The longitudinal case study method is well suited to capture the richness and complexity of these processes (Holmes and Poole, 1991; Yin, 1994). Following Glaser and Strauss (1967) that researchers need to consider their theoretical purpose in selecting cases, we use China as our data source. In the global scale China offers an interesting case to study. China has the largest GSM network in the world. But its $2.5 \mathrm{G}$ market size is very small. Most parts of China's mobile telecommunications market will move from $2 \mathrm{G}$ to $3 \mathrm{G}$ directly. Now the government is organizing pilot tests on different $3 \mathrm{G}$ standards so as to decide $3 \mathrm{G}$ licenses.

Our framework is designed for an in-depth longitudinal case study, for which we have not finished the fieldwork yet. In this section we limit our aim to using secondary data to demonstrate the explanatory power of our framework, and hereby seek the necessity to improve it. We also want to solicit guidance for using it in field study in the future. We select our data source from a recent issue of Communications of The ACM (Yan, 2003), which provide a concise but comprehensive description on the mobile telecommunications market innovation in China. By "comprehensive" we mean that ideally the selected papers cover the three themes described by our framework, including the interrelated processes of infrastructure innovation and innovation adoption, as well as the social network around these processes. We dissect the papers and code their data according to our framework. Table 2, 3 and 4 condense our analysis.

Table 2. Mobile telecommunications market development

\begin{tabular}{ll}
\hline & \multicolumn{1}{c}{ Market development } \\
\hline Adoption & $\begin{array}{l}\text { An advanced but less user-friendly technology like WAP is not necessarily } \\
\text { more commercially viable than basic but easy-to-use ones like SMS }\end{array}$ \\
Innovation & $\begin{array}{l}\text { Monternet is a system of innovation. WAP fails to form a system of innovation } \\
\text { Dynamics }\end{array}$ \\
& $\begin{array}{l}\text { Generally adoption and innovation are treated as two independent traits of } \\
\text { iMode diffusion. It mentions that the success of SMS leads operator to launch } \\
\text { Monternet }\end{array}$ \\
\hline
\end{tabular}

Table 3. Social system for market development

\section{Social system}

\begin{tabular}{ll}
\hline Providers & Cooperation between China Telecom, HP, content providers \\
Users & Addressed \\
Institutions & Not mentioned \\
Interplay between & The operator and a vendor jointly construct an infrastructure called \\
social system and & Aspire, and in return the Aspire platform shapes the relation \\
market innovation & between the operator, service providers, and content providers \\
\hline
\end{tabular}


Table 4. Research questions addressed in case paper

\section{Research questions addressed}

Question 1 It has identified the operator, content providers and vendor as major actors, and analyzed their interaction and specific roles

Question 2 It provides a static picture on SMS and WAP diffusion from innovation and adoption perspectives. SMS is an example that adoption influences innovation

Question 3 It has examined interplay between market and social system in the case of Monternet

\subsection{Case description}

One key argument of the author is that "an advanced but less userfriendly technology like WAP is not necessarily more commercially viable than basic but easy-to-use ones like SMS" (Yan, 2003, p. 84). In China SMS usage volume increased from 126.7 million messages in the first half of 2000 to 40.69 billion messages in the first half of 2003. The author attributes the success of SMS to six factors: 1) It is an economical way to communicate; 2) It is useful in special circumstances, like in a conference when its use will not disturb others; 3) It is better at expressing certain information than verbal media, like delivering greeting on Chinese New Year; 4) It is more suitable for broadcasting information; 5) The Chinese users are reluctant to leave voice messages; 6) It is a tool to distribute jokes and adult humor among subscribers, which are prohibited in the public media. In contrast, the diffusion of WAP is a failure. In contrast, only $2 \%$ of Chinese subscribers access Internet via a WAP phone, which is the lowest percentage of the Asia-Pacific economies. This is due to that WAP uses WML language for programming content hence it creates a big switching cost for content providers. As a result the content is limited. Meanwhile WAP runs over circuit-switched networks with low transmission speeds and per-minute charging, which makes it have a very limited value for the users.

The Monternet program introduced by China Mobile from November 2000 plays a key role for the booming of mobile data communications based on SMS. Known as the "one-stop shop, China-wide service" arrangement, it allows information service providers to access the operator's mobile network at any place and time to provide nation-wide services. Following iMode, it has a simple revenue sharing model between the operator and content providers, which is that China Mobile keeps $9 \%$ of traffic revenue. In order to facilitate Monternet, in 2000 China Mobile set up a subsidiary called Aspire with Hewlett-Packard that owns 7\% of the company. Aspire built the Mobile Information Service Center (MISC) to serve as the common platform for all of China Mobile's mobile Internet services. It was installed on the basis of the distributed structure of China Mobile's provincial operating subsidiaries. A unified MISC platform provides mobile subscribers with 
mobile data-roaming capabilities throughout China. MISC also provides a uniform data interface open to third-party service providers, through which standard network information, including billing, is provided. Segregating service platforms from basic mobile communication services ensures that all mobile communications networks developed through the platform migrate smoothly when they are upgraded to $2.5 \mathrm{G}$ and $3 \mathrm{G}$ networks, making them truly forward-compatible networks. Monternet generated an overwhelming response from service providers. As an illustration, by the end of 2000, more than $\mathbf{5 0 0}$ had joined. Especially after China Mobile upgraded the circuitswitching network to a packet-based network, more advanced mobile valueadded services like MMS are now available. As a result the mobile data communications market has kept a fast development.

\subsection{Case analysis}

The six factors for the market success of SMS fall in the category of user adoption. Moreover, this paper attributes the fast development of SMS to Monternet program, which presents a successful case of systems of innovation. Furthermore, the author attributes its development to the efficient interplay between technology innovation and the social system: the operator and a manufacture cooperate to construct an infrastructure called Aspire, and in return the Aspire platform shapes the relation between the operator, service providers and content providers.

The failure of WAP has been explained from adoption perspective that claims that it has limited user values because of low transmission speeds and per-minute charging method. From the innovation perspective content providers hesitate to participate in the market because of high switching cost, and as a result the system of innovation has not been formed.

It has mentioned that the success of SMS encourages the operator to launch Monternet. Unfortunately in this paper has not deeply examined the interrelation between the innovation and adoption processes argued by our model. By inference, as SMS is welcomed by the user, it encourages the operator to invest in technology innovation, which in return promotes the continuous fast development of SMS and other related mobile data communications services. However, for the case of WAP such a cycle of efforts does not exist. This paper is purely a description without any theoretical support. Yet, obviously the facts it gives can be better interpreted using our framework. 


\section{DISCUSSION AND CONCLUSION}

As Barnes and Huff (2003, p.84) have observed in studying iMode market in Japan: though technology adoption theories help us understand how characteristics of technology, factors underlying the behavioral norms, and industry features have driven the rapid market development, it needs a comprehensive framework to explain how these factors together forge market innovation. In this paper we move one step towards this aim. Our framework integrates adoption and innovation perspectives. It calls for a dynamic description on the process of innovation and adoption, and a focus on the interrelation of these two processes. It encourages disclosing the interplay of mobile telecommunications market innovation and its social systems. Our framework enables the researchers to have a systematic description on a diffusion issue. It offers a higher explanatory power compared with a traditional innovation or adoption theory.

We have used the case of China to justify our framework. We find the case paper only addresses part of the questions that should be covered by our model (see section 3 ). It notices that adoption and innovation are necessary perspectives to analyze a diffusion process, and observe social systems are an important dimension to analyze a diffusion process. However, basically it omits the interplay between social systems and market development, and interrelation between adoption and innovation. Their analyses are static in nature.

One conclusion is that our model has a high explanatory power to analyze the diffusion of mobile technologies. Currently we are drawing upon this model to engage in an in-depth field study on mobile telecommunications market development in different countries including China. We aim to generate market innovation patterns by comparing the answers of different countries to our research questions enumerated in section 3. Moreover, following the principle of dialogical reasoning we will rationalize the present theoretical assumptions about mobile telecommunications market innovation as the data collection moves forwards. During this process, we open the opportunities of improving our model so as to make it generally applicable to studying other networked technologies (Klein and Myers, 1999).

\section{ACKNOWLEDGEMENT}

This research was conducted as a part of Mobiconomy project at Copenhagen Business School. Mobiconomy is partially supported by the Danish Research Agency, grant number 2054-03-0004. 


\section{REFERENCES}

Ajzen, I. Understanding Attitude and Predicting Social Behavior, Prentice-Hall, 1980.

Anckar, B., D'Incau, D. "Value Creation in Mobile Commerce: Findings from a Consumer Survey", Journal of Information Technology Theory and Application, (4:1), 2002, pp. 4364.

Arthur, W.B. "Competing Technologies, Increasing Returns and Lock-in by Historical Events", Economic Journal, 99, 1989, pp. 116-131.

Arthur, W.B. "Positive Feedbacks in the Economy", Scientific American, (262:2), 1990, pp. 80-85.

Attewell, P. "Technology Diffusion and Organizational Learning: the Case of Business Computing", Organization Science, (3:1), 1992, pp. 1-19.

Barnes, S.J., Huff, S.L. "Rising Sun: iMode and the Wireless Internet", Communications of the $A C M$, (46:11), 2003, pp. 79-84.

Choudrie, J., Papazafeiropoulou, A., Lee, H. "A Web of Stakeholders and Strategies: A Case of Broadband Diffusion in South Korea", Journal of Information Technology, (18.4), 2003, pp.281-290.

Ciborra, C.U. From Control to Drift: the Dynamics of Corporate Information Infrastructures, Oxford University Press, 2000.

Damsgaard, J. "Managing an Internet portal", Communications of the AIS, (9:26), 2002, pp. 408-420.Davis, F.D. "Perceived Usefulness, Perceived Ease of Use, and User Acceptance of Information Technology", MIS Quarterly, (13:3), 1989, pp. 319-340.

Dosi, G., Freeman, C., Nelson, R., Soete, L. Technical Change and Economic Theory, 1988.

Edquist, C. Systems of Innovation: Technologies, Institutions, and Organizations, 1997.

Edquist, C. The Internet and Mobile Telecommunications Systems of Innovation, UK: Edward Elgar, 2003.

Funk, J.L., Methe, D.T. "Market- and Committee-based Mechanisms in the Creation and Diffusion of Global Industry Standards: the Case of Mobile Communication", Research Policy, 30, 2001, pp. 589-610.

Glaser, B.G., Strauss, A.L. The Discovery of Grounded Theory: Strategies for Qualitative Research, New York: Aldine Publishing Company, 1967.

Holmes, M., Poole, M.S. "The Longitudinal Analysis of Interaction", in Studying Interpersonal Interaction, B. Montgomery and S. Duck (eds.), New York: Guilford, 1991.

King, J.L., Gurbaxani, V., Kraemer, K.L., McFarlan, F.W., Raman, K.S., Yap, C.S. "Institutional Factors in Information Technology Innovation", Information Systems Research, (5:2), 1994, pp. 139-169.

Klein, H. K, Myers, M.D. "A Set of Principles for Conducting and Evaluating Interpretive Field Studies in Information Systems", MIS Quarterly, (23:1), 1999, pp. 67-93.

Lyytinen, K., Damsgaard, J. "What's Wrong with the Diffusion of Innovation Theory"? in Diffusing Software Product and Process Innovations, M.A. Ardis and B.L. Marcolin (eds.), Kluwer Academic Publishers, 2001, pp. 173-190.

Muller-Veerse, F. Mobile Commerce Report, London: Durlacher Research Ltd, 2000.

Oliva, T.A. "Technological Choice under Conditions of Changing Network Externality", The Journal of High Technology Management Research, (5:2), 1994, pp. 279-298. 
Pedersen, A.F., Andersen, K.V., Jelbo, C. "The Paradox of the Mobile Internet: Acceptance of Gadgets and Rejection of Innovations", Proceedings of 16th Bled eCommerce Conference, 2003.

Rogers, E.M. Diffusion of Innovations, New York: The Free Press, 1995.

Shapiro, C., Varian, H.R. Information Rules: A Strategic Guide to the Network Economy, Boston, Mass.: Harvard Business School Press, 1999.

Star, S.L. and Ruhleder, K. "Steps toward Ecology of Infrastructure: Design and Access for Large Information Spaces", Information Systems Research, (7:1), 1996, pp. 111-134.

Tornatzky, L.G., Klein, K.J. "Innovation Characteristics and Adoption-Implementation", IEEE Transactions on Engineering Management, (29:1), 1982, pp. 28-45.

Van de Ven, A.H. "A Community Perspective on the Emergence of Innovations", Journal of Engineering and Technology Management, (10,) 1993, pp. 23-51.

Wolfe, R.A. "Organizational Innovation: Review, Critique and Suggested Research Directions", Journal of Management Studies, (31:3), 1994, pp. 405-431.

Yan, X. "Mobile Data Communications in China", Communications of the ACM, (46:12), 2003, pp. 81-85.

Yin, R. K. Case Study Research: Design and Methods, Thousand Oaks, CA: Sage, 1994. 